\title{
The role of heart rate and ivabradine in acute heart failure
}

\author{
Edoardo Sciatti, Enrico Vizzardi, Lucia Dallapellegrina, Ivano Bonadei, Valentina Carubelli \\ Cardiology Unit, Department of Medical and Surgical Specialties, Radiological Sciences and Public Health, University \\ of Brescia; Cardio-Thoracic Department, ASST Spedali Civili, Brescia, Italy
}

\begin{abstract}
Resting heart rate (HR) is considered a powerful predictor of mortality both in healthy subjects and in cardiovascular (CV) patients, including those affected by heart failure (HF). Its reduction below $70 \mathrm{bpm}$ is the treatment target in chronic HF with reduced ejection fraction (HFrEF) when sinus rhythm is present. In acute HF (AHF) HR is usually elevated but its role as risk marker is still unknown. Notably, in unstable patients, beta-blockers can be reduced or stopped, thus enhancing this phenomenon. Moreover, some data in literature suggest that HR reduction during hospitalization or HR at discharge or in the vulnerable phase after it are more predictive of early-term events and may be therapeutic targets. On the other hand, ivabradine is a pure HR-lowering drug with no effects on inotropism. Its role in the AHF setting has been recently investigated and is the object of this review.
\end{abstract}

\section{Pharmacology of ivabradine and current indications}

Ivabradine is the only pure heart-lowering drug on commerce [1]. It acts specifically blocking the $\mathrm{I}_{f}$ ("funny") current in the sinoatrial node [2], where myocytes have the unique ability to

\footnotetext{
Correspondence: Dr. Edoardo Sciatti, University of Brescia and ASST Spedali Civili, Piazzale Spedali Civili 1, 25123 Brescia, Italy. Tel. +39.030.3995536 - Fax: +39.030.3995013. E-mail:

edoardo.sciatti@gmail.com
}

Key words: Heart rate; ivabradine; acute heart failure; beta-blockers; prognosis; tachycardia.

Conflict of interest: the authors declare no conflict of interest.

Received for publication: 9 May 2019.

Accepted for publication: 18 September 2019.

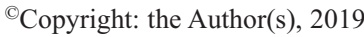

Licensee PAGEPress, Italy

Monaldi Archives for Chest Disease 2019; 89:1091

doi: 10.4081/monaldi.2019.1091

This article is distributed under the terms of the Creative Commons Attribution Noncommercial License (by-nc 4.0) which permits any noncommercial use, distribution, and reproduction in any medium, provided the original author(s) and source are credited. generate a spontaneous slow diastolic depolarization in order to provide a subsequent action potential. Ivabradine has a high selectivity for $\mathrm{I}_{f}$ channels [2] blocking them by entering their pore from the intracellular side in a concentration-dependent manner only when the channel is open $[3,4]$. It reduces the firing rate of the pacemaker cells in the sinoatrial node without affecting the duration of the action potential and without interfering with other ionic currents [3,5]. Consequently, ivabradine has no effects during atrial fibrillation (AF). Moreover, being $\mathrm{I}_{f}$ inhibition dependent from the frequency of channel opening, from the voltage and the sodium concentration, ivabradine is more effective at a higher HR [4].

In the SHIFT (Systolic Heart failure treatment with the I(f) inhibitor ivabradine Trial) 6505 outpatients affected by chronic heart failure (HF) with left ventricular (LV) ejection fraction (EF) $\leq 35 \%$ and $\mathrm{HR} \geq 70 \mathrm{bpm}$ in sinus rhythm (SR) were randomized to ivabradine (target dose $7.5 \mathrm{mg}$ bid) or placebo on top of standard medical therapy [6]. Ivabradine reduced by $18 \%$ the primary composite endpoint of cardiovascular $(\mathrm{CV})$ death or worsening HF, mainly acting on $\mathrm{HF}$ rehospitalisation and HF death. In a subsequent analysis of the SHIFT trial regarding the subgroup with $\mathrm{HR} \geq 75 \mathrm{bpm}$ all-cause mortality and CV mortality were both decreased by $17 \%$, suggesting that the higher the resting HR the more beneficial the effect of the drug [7]. Similar analyses in the pooled population from the SHIFT and the BEAUTIFUL trials confirmed the same findings [8].

In the setting of HF, beta-blockers are one of the first line therapy (recommendation class IA) and reduce mortality and morbidity but have not been tested in congest or decompensated patients. Beta-blockers should be initiated in clinically stable patients at a low dose and gradually up-titrated to the maximum tolerated dose. In patients admitted due to acute HF (AHF) betablockers should be cautiously initiated in hospital, once the patient is stabilized [9] and the dose might be halved if worsening sign and symptoms of HF to facilitate recovery [10]. According to the results of the SHIFT and the BEAUTIFUL trials, in the recent European Society of Cardiology (ESC) guidelines ivabradine has a class of recommendation IIa to reduce $\mathrm{CV}$ mortality and $\mathrm{HF}$ hospitalization in symptomatic patients with $\mathrm{LVEF} \leq 35 \%$ and resting $\mathrm{HR} \geq 70 \mathrm{bpm}$ in SR despite the maximum tolerated dose of beta-blocker, ACE inhibitor (or angiotensin receptor blocker) and mineralocorticoid receptor antagonist (or angiotensin receptor blocker) (level of evidence B) or in those not tolerating or having contraindications to beta-blocker, already receiving ACE inhibitor (or angiotensin receptor blocker) and mineralocorticoid receptor antagonist (or angiotensin receptor blocker) (level of evidence C) [9].

\section{Heart rate in chronic heart failure: brief overview}

With blood pressure, HR is a major clinical sign in the evaluation of CV patients. Albeit being simple and immediate, HR 
uncovers most information about the hemodynamic status of the patient, particularly if affected by HF. From this point of view, HR can be seen as a biological marker of LV deterioration, thus predicting a higher incidence of events and representing an important therapeutic target.

Resting HR, particularly nocturnal, is considered a powerful predictor of mortality in healthy subjects $[11,12]$. Indeed, the Framingham study showed a $14 \%$ increase in the all-cause mortality for every $10 \mathrm{bpm}$ increment in the basal $\mathrm{HR}$ and an increased risk of developing $\mathrm{HF}$ in people with $\mathrm{HR}>80 \mathrm{bpm}$ [13]. Moreover, every 1 -bpm in resting HR accounted for a $4 \%$ increase in the risk of developing LV dysfunction and HF in the asymptomatic participants of the MESA (Multi-Ethnic Study of Atherosclerosis) [14].

HR has a prognostic role in chronic HF patients with LV dysfunction in a non-linear manner [15,16]. Over $70 \mathrm{bpm}$, an increment in resting HR of 1 and $5 \mathrm{bpm}$ has been linked to a higher cumulative risk of death for $\mathrm{CV}$ causes and to a higher rate of hospitalizations for $\mathrm{HF}$, of 3 and $16 \%$ respectively [15]. In the control group of the SHIFT patients with the highest HR ( $\geq 87 \mathrm{bpm})$ were at more than 2-fold higher risk for the primary composite endpoint than were patients with the lowest HR (70-71 bpm) [15].

The optimization of medical therapy in real world HF patients is unsatisfactory due to the high complexity of such patients (e.g., comorbidities) with respect to those enrolled in randomized clinical trials $[6,17-20]$. In this context ivabradine is a powerful tool to better control HR and reduce mortality [21]. It seems that about $12 \%$ of HF outpatients need treatment with ivabradine after medical therapy optimization $[22,23]$. Interestingly, in a sub-analysis of the SHIFT, the benefit of ivabradine was maintained also in non-adherent or becoming non-adherent patients during the trial, suggesting that also reducing the $\mathrm{HR}$ for a short period might provide prolonged beneficial effects [24].

\section{Heart rate and ivabradine during hospitalization for acute heart failure}

The role of HR as a new therapeutic target is emerging in the context of AHF. European and Italian registries showed that patients admitted with AHF have higher basal HR as compared to patients with chronic HF $[25,26]$. However, Literature is still controversial regarding the prognostic significance of basal HR in patients hospitalized for AHF. For example, in the PROTECT (Adenosine A1 Receptor Antagonist Rolofylline in Patients with Acute Heart Failure and Renal Impairment) study, basal HR was shown to be part of model designed to predict the occurrence of adverse events at 7 days [27]. Bertomeu-Gonzalez et al. observed that at admission high HR was predictive of worse prognosis in patients with AF, but not in those with SR [28]. A J-shaped relationship between HR at admission and in-hospital mortality was found by Bui et al., with 70-75 bpm as the HR range with the lowest risk [29]. They also observed that an early HR reduction during the first days of hospital stay is predictive of better prognosis. However, when long-term events were considered, HR at admission was shown to lose its predictive value $[18,26]$. This could be explained by the fact that HR at admission is a hallmark of hemodynamic status and neurohormonal storm, both improving in parallel with decongestion. In the Acute HEArt Failure Database (AHEAD) Main registry, authors compared patients admitted for AHF by the presence of hypertensive HF, acute pulmonary oedema, cardiogenic shock, high output HF and right ventricular HF, observing a mean HR of 132 bpm in high output HF, whereas HR ranged from 90 to 98 bpm in the other situations. At discharge, $\mathrm{HR}>80 \mathrm{bpm}$ was a significant predictor of early mortality with HR 1.33 [30].

Moreover, a higher HR is related to sympathetic overactivity, greater oxygen consumption and lower myocardial coronary perfusion time [31], as well as increased shear stress with inflammatory endothelial response [32]. Of note, as shown regarding natriuretic peptides, the magnitude of the initial neurohormonal activation is not related to the patient's conditions at the time of discharge [33], but the variation during hospitalization and the value at discharge are much more related to long-term prognosis [33-35]. The same, a reduction in HR during hospital stay was shown to be protective against the development of long-term events, independently of the target achieved [36], as well as early post-discharge HR does [37,38]. Therefore, clinical stabilization until discharge of patients admitted for AHF is a crucial period in which HR control should be pursued. Real world data, as in chronic HF setting, show that HR $<70 \mathrm{bpm}$ is achieved in less than $50 \%$ at discharge [39], with beta-blockers at target dose only in $25 \%$ of patients [25]. However, it must be noted that some studies demonstrated that the benefit associated with beta-blockers is mainly related to the achievement of $\mathrm{HR}$ control than the recommended dose of beta-blockers $[40,41]$.

In AHF a higher HR is both a compensatory mechanism against hypotension and a contributor to worsening $\mathrm{HF}$, so that indication of lowering HR drugs is not clear. Lourenco et al. demonstrated that a higher admission heart rate predicted survival advantage in acute HF. Patients with heart rate $\geq 100 \mathrm{bpm}$ had a multivariate-adjusted HR of 12 -month death of 0.57 (95\%CI: $0.39-0.81)$, and the HR was $0.92(0.85-0.98)$ per $10 \mathrm{bpm}$ increase in heart rate. Patients presenting with tachycardia and discharged with a controlled heart rate had better outcome than those admitted non-tachycardic or discharged with a non-controlled heart rate (death rate was $14.9 \%$ and $37.7 \%$, respectively). Association of heart rate with mortality was stronger in patients in SR and in those with systolic dysfunction [42]. In a small cohort of AHF patients not needing inotropes ivabradine safely reduced HR improving New York Heart Association (NYHA) functional class and natriuretic peptides level [43]. The same was retrospectively found by Pascual Izco et al. [44]. Furthermore, the ETHIC-AHF trial randomized 71 AHF patients with $\mathrm{LVEF}<40 \%$ and SR with $\mathrm{HR}>70 \mathrm{bpm}$ to receive ivabradine and beta-blockers vs beta-blockers alone 24 hours after hospital admission. HR at one and 4 months after discharge were significantly lower in the first group, and significant differences were found with respect to LVEF and natriuretic peptides levels, but the trial did not found differences in clinical events (rehospitalization/death) at 4 months [45]. In addition, ivabradine, as a pure HR-lowering drug without negative effects on inotropism, can be useful to counteract inotrope-induced sinus tachycardia which often prevent patient's stabilization $[44,46,47]$ and does not have the limitations of beta-blockers and non-dehydropiridine calcium channel blockers. Cavusoglu et al. ran an ECG Holter monitoring in 58 AHF patients since the beginning of dobutamine therapy, half of them treated with ivabradine. They found that in the control group, mean HR gradually and significantly increased at each step of dobutamine infusion whereas no significant increase in HR was observed in the ivabradine group [48].

Recently, Colucci et al. suggested that for patients who are already taking ivabradine, management depends upon the severity of HF decompensation, heart rate and hemodynamic instability. If an increased heart rate appears necessary to maintain cardiac output, then may be considered holding ivabradine in patients with severe decompensation [49]. Contrarily, this agent should not be initiated at the time of presentation with an episode of ADHF. Based on the 
above-mentioned studies, during hospitalization ivabradine can be added on top of beta-blocker therapy to improve HR control if the latter are poorly tolerated or contraindicated. Unfortunately, no studies are available on the timing need for reaching the HR target $<70 /$ m. Safety and efficacy of this drug must be confirmed by focused clinical trials.

In the setting of acute peripartum cardiomyopathy a retrospective study from a German national registry found that those patients treated with ivabradine soon after diagnosis had a better prognosis compared with that reported so far in registries from Germany, United Kingdom and South Africa [50].

It is also important considerer that $\mathrm{AF}$ is the most frequent arrhythmia in patients with HF irrespective of LV ejection fraction, can impair LV function leading to worsening symptoms and can also be a precipitant cause in AHF [9], ranging from 5\% in mild to $10-26 \%$ in moderate and up to $50 \%$ in severe HFrEF [51,52]. It was observed in a 1-year follow-up a prevalence of $44 \%$ in chronic HF ad of $38 \%$ in AHF [53]. In the setting of AF Ivabradine should not be administered because it has no effect on HR, as the atrial rhythm derives from a chaotic electrical activation and is not liked to $\mathrm{I}_{f}$ ionic current. Moreover, in patients at risk of developing AF, the drug is not indicated because it increases the risk of AF itself. In a metanalysis, ivabradine treatment was associated with a relative risk of AF of 1.15 (95\% CI 1.07 to $1.24, \mathrm{p}=0.0027)$ among 21571 patients considered, estimating that the number needed to harm for ivabradine would be 208 ( $95 \%$ CI 122 to 667) per year of treatment [54]. This can represent an important limitation of the use of ivabradine in the clinical practice, reducing the potential number of patients that could benefit of the HR reduction induced.

\section{The setting of cardiogenic shock: few evidences}

Trials in cardiogenic shock are always difficult since the complexity of such patients. Few cases report about ivabradine use in this setting: one related with tachycardiomyopathy after heart transplantation [55], one with idiopathic cardiomyopathy [56] and some with acute myocardial infarction, also by our group [57,58]. Barillà et al. ran a pilot trial about ivabradine administration in patients with cardiogenic shock complicating ST-elevation myocardial infarction, founding that it can be effectively administered by nasogastric intubation and it is associated with a short-term favorable outcome in term of better recovery of LVEF [59]. In 2011 the MODI(f)Y trial has been presented as a prospective single center open label randomized controlled phase II trial to evaluate the effect of ivabradine in patients with multi-organ dysfunction syndrome, but results have not been published yet [60].

\section{Heart rate and ivabradine in the early post-discharge phase}

The vulnerable phase after AHF corresponds to the first 90 days after discharge, when re-hospitalizations are frequent and related to failure of achieving medical therapy optimization during the hospital stay, inadequate home care assistance or compliance to medical therapy and advanced status of the disease [61]. Such early re-hospitalizations are related to $\mathrm{CV}$ causes or other comorbidities and account up to $25 \%$ out of discharges after AHF $[37,62,63]$. As mentioned above, HR in the early post-discharge phase has a prognostic significance [37,38]. A post-hoc analysis of the EVEREST (Efficacy of Vasopressin Antagonism in Heart Failure: Outcome Study with Tolvaptan) trial revealed that in the early predischarge increases of HR $>70 \mathrm{bpm}$ were independent predictors of mortality during the early follow-up in patients with SR and LV dysfunction who had been admitted for AHF and previous chronic HF [18]. Moreover, every 5-bpm increment in HR in the first week and at four weeks post-discharge were independently associated with a $13 \%$ and $12 \%$ increased of overall mortality at a median follow-up of 10 months, respectively [18]. The EFFECT-HF (Enhanced Feedback for Effective Cardiac Treatment) program enrolled $9000 \mathrm{HF}$ patients after discharge from a phase of clinical deterioration. In this context, Habal et al. found a significant correlation between HR and early mortality, particularly if HR was $>80$ bpm [64]. The AHA GWTG-HF (American Heart Association Get with the Guidelines Program) prospective registry included 46,000 patients with the same characteristics and highlighted a correlation between HR at discharge and the likelihood of rehospitalization for all-causes, both in patients in SR and in AF [65]. In addition, a sub-analysis of this registry performed on more than 39000 patients admitted for AHF with or without LV systolic dysfunction included HR as in-hospital independent prognostic factor, together with age, HF as the cause of hospital admission, systolic blood pressure at admission, plasma sodium concentration, serum creatinine levels, and LVEF $<40 \%$ [66]. Other similar good prognostic scores, however, did not include HR [67-69]. A post-hoc analysis of the SHIFT evaluating the impact of chronic exposure to ivabradine on early readmissions during the vulnerable period showed that ivabradine was associated with $20-30 \%$ less all-cause hospitalizations at 1 month, 2 months and 3 months [70]. In the INTENSIFY study a group of 1,956 HFrEF patients with an initial $\mathrm{SR}(85 \pm 11 \mathrm{bpm})$ were treated with ivabradine, in $77.8 \%$ in addition to a beta-blocker and after 4 months of treatment, heart rate has fallen down to $67 \pm 8.9 \mathrm{bpm}$. In parallel with this heart rate reduction, the proportion of patients with signs of decompensation fell from $22.7 \%$ initially to $5.4 \%$, and the proportion of BNP levels $>400 \mathrm{pg} / \mathrm{mL}$ dropped from $53.9 \%$ to $26.7 \%$. This coincided with a reduction in NYHA class from $9.6 \%$ (I), $51.1 \%$ (II), 37.2\% (III) and $2.1 \%$ (IV) initially to $24.0 \%$ (I), $60.5 \%$ (II), $14.8 \%$ (III) and $0.7 \%$ (IV), respectively [71]. It is therefore reasonable to consider postdischarge $\mathrm{HR}$ as an important contributor in the prognostic stratifications of patients with a recent clinical decompensation of chronic HF.

\section{Conclusions}

In AHF patients HR during hospitalization, at discharge and early after discharge are associated with early-term events and can be a therapeutic target [36-48] and possible pros and cons of the use of ivabradine are summarized in Table 1. Ivabradine is approved in the setting of chronic HFrEF [9]. However, its pharmacological properties make the drug potentially useful also in the setting of AHF, where mortality and early re-hospitalization are still an important healthcare burden. The findings reported suggest that inhospital or early post-discharge initiation of ivabradine could be useful to improve early outcomes in patients hospitalized for AHF [70], even if proper clinical trials are still needed. The usefulness of ivabradine, compared with beta-blocker up-titration, with the addition of digoxin, or just with maintenance of ongoing therapy, is still unknown [72]. Certainly, ivabradine lets HR decrease without affecting inotropism and can counteract inotrope-induced 
Table 1. Heart rate and ivabradine in acute heart failure.

\begin{tabular}{|c|c|c|c|}
\hline Time & Meaning of high heart rate & Pros of ivabradine & Cons of ivabradine \\
\hline $\begin{array}{l}\text { Admission for acute heart failure } \\
\text { and first days of hospitalization }\end{array}$ & $\begin{array}{l}\text { Marker of hemodynamic instability } \\
\text { and neurohormonal storm } \\
\text { (unproved prognostic role) }\end{array}$ & $\begin{array}{l}\text { Prevents tachycardia-induced myocardial } \\
\text { ischemia when beta-blockers cannot be } \\
\text { uptitrated or administered (e.g., reduced } \\
\text { coronary perfusion in diastole, increased } \\
\text { oxygen consumption, plaque rupture/ } \\
\text { endothelial dysfunction, reduced contractility, } \\
\text { increased afterload) } \\
\text { Counteraction to inotrope-induced tachycardia }\end{array}$ & $\begin{array}{l}\text { May hinder the physiological } \\
\text { hemodynamic adaptation } \\
\text { mechanism induced by HR } \\
\text { increment (e.g., maintain } \\
\text { adequate blood pressure) }\end{array}$ \\
\hline $\begin{array}{l}\text { End of hospitalization and } \\
\text { vulnerable phase post-discharge }\end{array}$ & $\begin{array}{l}\text { Suboptimal therapy optimization } \\
\text { (independent prognosticator of } \\
\text { early-term outcomes) }\end{array}$ & $\begin{array}{l}\text { Favors HR }<70 \text { bpm reducing events } \\
\text { Prevents LV remodeling }\end{array}$ & $\begin{array}{l}\text { Increased risk of AF in patient } \\
\text { already at risk of AF itself } \\
\text { Side effects (e.g., symptomatic and } \\
\text { asymptomatic bradycardia and } \\
\text { conduction disturbances, } \\
\text { phosphenes, blurred vision) }\end{array}$ \\
\hline
\end{tabular}

AF, atrial fibrillation; $\mathrm{HF}$, heart failure; $\mathrm{HR}$, heart rate; $\mathrm{LV}$, left ventricular.

tachycardia in more compromised patients [46-48]. HR is easy and costless to monitor and, together with congestion, represents a major player in the outcomes of AHF patients [73]. Ivabradine is promising in AHF setting and needs further dedicated clinical trials to extend its indications in such patients.

\section{References}

1. Bonadei I, Vizzardi E, Sciatti E, et al. Is there a role for ivabradine beyond its conventional use? Cardiovasc Ther 2014;32:189-92.

2. Thollon C, Cambarrat C, Vian J, et al. Electrophysiological effects of S 16257, a novel sino-atrial node modulator, on rabbit and guinea-pig cardiac preparations: comparison with UL-FS 49. Br J Pharmacol 1994;112:37-42.

3. Bois P, Bescond J, Renaudon B, Lenfant J. Mode of action of bradycardic agent, S 16257, on ionic currents of rabbit sinoatrial node cells. Br J Pharmacol 1996;118:1051-7.

4. Bucchi A, Baruscotti M, DiFrancesco D. Current-dependent block of rabbit sino-atrial node I(f) channels by ivabradine. J Gen Physiol 2002;120:1-13.

5. Thollon C, Bidouard JP, Cambarrat C, et al. Stereospecific in vitro and in vivo effects of the new sinus node inhibitor $(+)-\mathrm{S}$ 16257. Eur J Pharmacol 1997;339:43-51.

6. Swedberg K, Komajda M, Böhm M, et al; SHIFT Investigators. Ivabradine and outcomes in chronic heart failure (SHIFT): a randomised placebo-controlled study. Lancet 2010;376:875-885.

7. Böhm M, Borer J, Ford I, et al. Heart rate at baseline influences the effect of ivabradine on cardiovascular outcomes in chronic heart failure: analysis from the SHIFT study. Clin Res Cardiol 2013;102:11-22.

8. Fox K, Komajda M, Ford I, et al. Effect of ivabradine in patients with left-ventricular systolic dysfunction: a pooled analysis of individual patient data from the BEAUTIFUL and SHIFT trials. Eur Heart J 2013;34:2263-70.

9. Ponikowski P, Voors AA, Anker SD, et al. 2016 ESC Guidelines for the diagnosis and treatment of acute and chronic heart failure: The Task Force for the diagnosis and treatment of acute and chronic heart failure of the European Society of Cardiology (ESC). Developed with the special contribution of the Heart
Failure Association (HFA) of the ESC. Eur J Heart Fail 2016;18:891-975.

10. Ponikowski P, Voors AA, Anker SD, et al. 2016 ESC Guidelines for the diagnosis and treatment of acute and chronic heart failure - Web Addenda: The Task Force for the diagnosis and treatment of acute and chronic heart failure of the European Society of Cardiology (ESC). Developed with the special contribution of the Heart Failure Association (HFA) of the ESC. Eur Heart J doi:10.1093/eurheartj/ehw128

11. Johansen CD, Olsen RH, Pedersen LR, et al. Resting, nighttime, and $24 \mathrm{~h}$ heart rate as markers of cardiovascular risk in middle-aged and elderly men and women with no apparent heart disease. Eur Heart J 2013;34:1732-9.

12. Mensink GB, Hoffmeister H. The relationship between resting heart rate and all-cause, cardiovascular and cancer mortality. Eur Heart J 1997;18:1404-10.

13. Kannel WB, Kannel C, Paffenbarger RS Jr, Cupples LA. Heart rate and cardiovascular mortality: the Framingham Study. Am Heart J 1987;113:1489-94.

14. Opdahl A, Ambale Venkatesh B, Fernandes VRS, et al. Resting heart rate as predictor for left ventricular dysfunction and heart failure: MESA (Multi-Ethnic Study of Atherosclerosis). J Am Coll Cardiol 2014;63:1182-9.

15. Böhm M, Swedberg K, Komajda M, et al. Heart rate as a risk factor in chronic heart failure (SHIFT): the association between heart rate and outcomes in a randomised placebo-controlled trial. Lancet 2010;376:886-94.

16. Fox K, Ford I, Steg PG, et al. Heart rate as a prognostic risk factor in patients with coronary artery disease and left-ventricular systolic dysfunction (BEAUTIFUL): a subgroup analysis of a randomised controlled trial. Lancet 2008;372:817-21.

17. Dobre D, Haaijer-Ruskamp FM, Voors AA, van Veldhuisen DJ. beta-Adrenoceptor antagonists in elderly patients with heart failure: a critical review of their efficacy and tolerability. Drugs Aging 2007;24:1031-44.

18. Greene SJ, Vaduganathan M, Wilcox JE, et al. The prognostic significance of heart rate in patients hospitalized for heart failure with reduced ejection fraction in sinus rhythm: insights from the EVEREST (Efficacy of Vasopressin Antagonism in Heart Failure: Outcome Study With Tolvaptan) trial. JACC Heart Fail 2013;1:488-96.

19. Borer JS, Böhm M, Ford I, et al. Effect of ivabradine on 
recurrent hospitalization for worsening heart failure in patients with chronic systolic heart failure: the SHIFT Study. Eur Heart J 2012;33:2813-20.

20. Shaaya G, Al-Khazaali A, Arora R. Heart rate as a biomarker in heart failure: Role of heart rate lowering agents. Am J Ther 2017;24:e532-e539.

21. Dobre D, Borer JS, Fox K, et al. Heart rate: a prognostic factor and therapeutic target in chronic heart failure. The distinct roles of drugs with heart rate-lowering properties. Eur J Heart Fail 2014; $16: 76-85$.

22. Dierckx R, Cleland JG, Parsons S, et al. Prescribing patterns to optimize heart rate: analysis of 1,000 consecutive outpatient appointments to a single heart failure clinic over a 6-month period. JACC Heart Fail 2015;3:224-30.

23. Borer JS. How many patients will benefit from a new therapy for chronic systolic heart failure, and what difference does it make? JACC Heart Fail 2015;3:231-3.

24. Böhm M, Lloyd SM, Ford I, et al. Non-adherence to ivabradine and placebo and outcomes in chronic heart failure: an analysis from SHIFT. Eur J Heart Fail 2016;18:672-83.

25. Maggioni AP, Dahlström U, Filippatos G, et al. EURObservational Research Programme: the Heart Failure Pilot Survey (ESC-HF Pilot). Eur J Heart Fail 2010;12:1076-84.

26. Tavazzi L, Senni M, Metra M, et al. Multicenter prospective observational study on acute and chronic heart failure: one-year follow-up results of IN-HF (Italian Network on Heart Failure) outcome registry. Circ Heart Fail 2013;6:473-81.

27. O'Connor CM, Mentz RJ, Cotter G, et al, The PROTECT inhospital risk model: 7-day outcome in patients hospitalized with acute heart failure and renal dysfunction. Eur J Heart Fail 2012; 14:605-12.

28. Bertomeu-González V, Núñez J, Núñez E, et al. Heart rate in acute heart failure, lower is not always better. Int $\mathrm{J}$ Cardiol 2010;145:592-3.

29. Bui AL, Grau-Sepulveda MV, Hernandez AF, et al. Admission heart rate and in-hospital outcomes in patients hospitalized for heart failure in sinus rhythm and in atrial fibrillation. Am Heart J 2013;165:567-74.e6

30. Parenica J, Spinar J, Vitovec J, Widimsky P, et al. Long-term survival following acute heart failure: the Acute Heart Failure Database Main registry (AHEAD Main). Eur J Intern Med 2013;24:151-60.

31. Fox K, Borer JS, Camm AJ, et al. Resting heart rate in cardiovascular disease. J Am Coll Cardiol 2007;50:823-30.

32. Traub O, Berk BC. Laminar shear stress: mechanisms by which endothelial cells transduce an atheroprotective force. Arterioscler Thromb Vasc Biol 1998;18:677-85.

33. Broqvist M, Dahlström U, Karlberg BE, et al. Neuroendocrine response in acute heart failure and the influence of treatment. Eur Heart J 1989;10:1075-83.

34. Metra M, Cotter G, Davison BA, et al. Effect of serelaxin on cardiac, renal, and hepatic biomarkers in the Relaxin in Acute Heart Failure (RELAX-AHF) development program: correlation with outcomes. J Am Coll Cardiol 2013;61:196-206.

35. Metra M, Nodari S, Parrinello G, et al. The role of plasma biomarkers in acute heart failure. Serial changes and independent prognostic value of NT-proBNP and cardiac troponin-T. Eur J Heart Fail 2007;9:776-86.

36. Takahama H, Yokoyama H, Kada A, et al. Extent of heart rate reduction during hospitalization using beta-blockers, not the achieved heart rate itself at discharge, predicts the clinical outcome in patients with acute heart failure syndromes. J Cardiol 2013;61:58-64.
37. Gheorghiade M, Vaduganathan M, Fonarow GC, Bonow RO. Rehospitalization for heart failure: problems and perspectives. J Am Coll Cardiol 2013;61:391-403.

38. Metra M, Gheorghiade M, Bonow RO, Dei Cas L. Postdischarge assessment after a heart failure hospitalization: the next step forward. Circulation 2010;122:1782-5.

39. Farmakis D, Parissis J, Karavidas A, et al. In-hospital management of acute heart failure: Practical recommendations and future perspectives. Int J Cardiol 2015;201:231-6.

40. Swedberg K, Komajda M, Böhm M, et al. Effects on outcomes of heart rate reduction by ivabradine in patients with congestive heart failure: is there an influence of beta-blocker dose? Findings from the SHIFT (Systolic Heart failure treatment with the I(f) inhibitor ivabradine Trial) study. J Am Coll Cardiol 2012;59:1938-45.

41. Cullington D, Goode KM, Clark AL, Cleland JG. Heart rate achieved or beta-blocker dose in patients with chronic heart failure: which is the better target? Eur J Heart Fail 2012;14:737-47.

42. Lourenco P, Ribeiro A, Cunha F, et al. Is there a heart rate paradox in acute heart failure? Int J Cardiol 2015;203:409-14.

43. Sargento L, Satendra M, Longo S, et al. Heart rate reduction with ivabradine in patients with acute decompensated systolic heart failure. Am J Cardiovasc Drugs 2014;14:229-35.

44. Pascual Izco M, Alonso Salinas GL, Sanmartín Fernández M, et al. Clinical Experience with Ivabradine in Acute Heart Failure. Cardiology 2016;134:372-4.

45. Hidalgo FJ, Anguita M, Castillo JC, et al. Effect of early treatment with ivabradine combined with beta-blockers versus beta-blockers alone in patients hospitalised with heart failure and reduced left ventricular ejection fraction (ETHIC-AHF): A randomised study. Int J Cardiol 2016;217:7-11.

46. Lattuca B, Roubille F. Ivabradine: a promising drug in cardiogenic shock to prevent the undesirable sinus tachycardia induced by dobutamine? Int J Cardiol 2015;178:308-10.

47. Link A, Reil JC, Selejan S, Böhm M. Effect of ivabradine in dobutamine induced sinus tachycardia in a case of acute heart failure. Clin Res Cardiol 2009;98:513-5.

48. Cavusoglu Y, Mert U, Nadir A, et al. Ivabradine treatment prevents dobutamine-induced increase in heart rate in patients with acute decompensated heart failure. J Cardiovasc Med (Hagerstown) 2015;16:603-9.

49. Colucci WS. Treatment of acute decompensated heart failure: Components of therapy. UpToDate [Internet]. Available from: https://www.uptodate.com/contents/treatment-of-acutedecompensated-heart-failure-components-of-therapy

50. Haghikia A, Tongers J, Berliner D, et al. Early ivabradine treatment in patients with acute peripartum cardiomyopathy: Subanalysis of the German PPCM registry. Int J Cardiol 2016;216:165-7.

51. Anter E, Jessup M, Callans DJ. Atrial fibrillation and heart failure: treatment considerations for a dual epidemic. Circulation 2009;119:2516-25.

52. Maisel WH, Stevenson LW. Atrial fibrillation in heart failure: epidemiology, pathophysiology, and rationale for therapy. Am J Cardiol 2003;91:2-8D.

53. Crespo-Leiro M.G, Anker S.D, Maggioni A. P, et al. European Society of Cardiology Heart Failure Long-Term Registry (ESCHF-LT): 1-year follow-up outcomes and differences across regions. Eur J Heart Fail 2016;18:613-25.

54. Martin RIR, Pogoryelova O, Santibáñez Koref M, et al. Atrial fibrillation associated with ivabradine treatment: meta-analysis of randomised controlled trials. Heart 2014;100:1506-10. 
55. Zwicker C, Becker M, Lepper W, et al. Cardiogenic shock due to tachycardiomyopathy after heart transplantation: successful treatment with ivabradine. Cardiology 2010;116:174-7.

56. Roubille F, Lattuca B, Busseuil D, et al. Is ivabradine suitable to control undesirable tachycardia induced by dobutamine in cardiogenic shock treatment? Med Hypotheses 2013;81:202-6.

57. Bonadei I, Sciatti E, Vizzardi E, et al. Ivabradine during cardiogenic shock: a clinical case and review of the literature. Heart Lung 2015;44:57-8.

58. Post F, Munzel T. [Ivabradine - a new therapeutic option for cardiogenic shock?].[Article in German] Herz 2009;34:224-9.

59. Barillà F, Pannarale G, Torromeo C, et al. Ivabradine in patients with ST-elevation myocardial infarction complicated by cardiogenic shock: A preliminary randomized prospective study. Clin Drug Investig 2016;36:849-56.

60. Nuding S, Ebelt H, Hoke RS, et al. Reducing elevated heart rate in patients with multiple organ dysfunction syndrome by the I (f) (funny channel current) inhibitor ivabradine: MODI (f)Y trial. Clin Res Cardiol 2011;100:915-23.

61. Abraham WT, Adamson PB, Bourge RC, et al; CHAMPION Trial Study Group. Wireless pulmonary artery haemodynamic monitoring in chronic heart failure: a randomised controlled trial. Lancet 2011;377:658-66.

62. Desai AS, Stevenson LW. Rehospitalization for heart failure: predict or prevent? Circulation 2012;126:501-6.

63. Joynt KE, Orav EJ, Jha AK. Thirty-day readmission rates for Medicare beneficiaries by race and site of care. JAMA 2011;305:675-81.

64. Habal MV, Liu PP, Austin PC, et al. Association of heart rate at hospital discharge with mortality and hospitalizations in patients with heart failure. Circ Heart Fail 2014;7:12-20.

65. Laskey WK, Alomari I, Cox M, et al. Heart rate at hospital discharge in patients with heart failure is associated with mortality and rehospitalization. J Am Heart Assoc 2015;4:e001626.

66. Peterson PN, Rumsfeld JS, Liang L, et al. A validated risk score for in-hospital mortality in patients with heart failure from the American Heart Association get with the guidelines program. Circ Cardiovasc Qual Outcomes 2010;3:25-32.

67. Scrutinio D, Ammirati E, Guida P, et al. The ADHF/NT-proBNP risk score to predict 1-year mortality in hospitalized patients with advanced decompensated heart failure. J Heart Lung Transplant 2014;33:404-11.

68. Scrutinio D, Ammirati E, Passantino A, et al. Predicting shortterm mortality in advanced decompensated heart failure - role of the updated acute decompensated heart failure/N-terminal proB-type natriuretic Peptide risk score. Circ J 2015;79:1076-83.

69. Ferrero P, Iacovoni A, D'Elia E, et al. Prognostic scores in heart failure - Critical appraisal and practical use. Int J Cardiol 2015;188:1-9.

70. Komajda M, Tavazzi L, Swedberg K, et al. Chronic exposure to ivabradine reduces readmissions in the vulnerable phase after hospitalization for worsening systolic heart failure: a post-hoc analysis of SHIFT. Eur J Heart Fail 2016;18:1182-9.

71. Zugck C, Martinka P, Stöckl G. Ivabradine treatment in a chronic heart failure patient cohort: symptom reduction and improvement in quality of life in clinical practice. Adv Ther 2014;31:961-974

72. Castagno D, Petrie MC, Claggett B, McMurray J. Should we SHIFT our thinking about digoxin? Observations on ivabradine and heart rate reduction in heart failure. Eur Heart $\mathrm{J}$ 2012;33:1137-41.

73. Metra M. Tachycardia after a heart failure hospitalization: another piece of the puzzle? JACC Heart Fail 2013;1:497-9. 